\title{
O Uso da Sustentabilidade como Argumento Legitimador da Artificialização da Natureza e do Social no Capitalismo Contemporâneo
}

\author{
The Use of Sustainability as an Argument for Legitimizing the artificialization of Nature \\ and Social in Contemporary Capitalism
}

\section{EI Uso de la Sostenibilidad como Argumento Legitimador de la Artificialización de la Naturaleza y del Social en el Capitalismo Contemporáneo}

\author{
Dweison Nunes Souza da Silva ${ }^{1}$ \\ Edvânia Tôrres Aguiar Gomes ${ }^{2}$
}

\begin{abstract}
Resumo
Considerando os antecedentes da crise social e ambiental contemporâneas como consequências de um processo estrutural de reprodução socioeconômica cujo solo fundante está no capitalismo, este artigo busca refletir sobre as contradições que emergem do pseudo imperativo socioambiental contemporâneo - a sustentabilidade em suas várias faces - cuja naturalização tem contribuído, sobremaneira, para o aumento de desigualdades sociais e degradações ambientais de uma maneira geral. Para tanto, se recorre a autores clássicos, artigos de periódicos científicos e páginas oficiais sobre o tema por meio de pesquisas documental e bibliográficas. Observa-se que o compromisso contemporâneo de promover atividades econômicas, em alguma medida conectadas à sólida $e$ duradoura prosperidade social e orientadas à conservação da natureza, se apresenta materialmente inconcebível. Logo, a sustentabilidade constituindo-se como mais uma estratégia no atual capitalismo, pela qual alguns agentes público-privados buscam legitimar um determinado status quo.
\end{abstract}

Palavras-chave: Capital. Políticas públicas. Desenvolvimento sustentável.

\begin{abstract}
Considering the antecedents of the contemporary social and environmental crisis as consequences of a structural process of socioeconomic reproduction whose founding ground is in capitalism, this article seeks to reflect on the contradictions that emerge from the contemporary socio-environmental pseudo imperative - sustainability in its various faces - whose naturalization has contributed greatly to the increase of social inequalities and environmental degradation in general. For this, classic authors, articles from scientific journals and official pages on the subject are used through documentary and bibliographical research. It is observed that the contemporary commitment to promote economic activities, to some extent linked to solid and lasting social prosperity with the conservation of nature, is materially inconceivable. Sustainability is therefore more a strategy in the current capitalism whereby some public-private agents seek to legitimize a given status quo.
\end{abstract}

Keywords: Capital. Public policies. Sustainable development.

\section{Resumen}

Considerando los antecedentes de la crisis social y ambiental contemporánea como consecuencia de un proceso estructural de reproducción socioeconómica cuyo suelo fundante está en el capitalismo, este artículo busca reflexionar sobre las contradicciones que emergen del pseudo imperativo socioambiental contemporáneo - la sustentabilidad en sus varias caras - cuya la naturalización viene contribuyendo, sobremanera, para el aumento de desigualdades sociales y degradaciones ambientales de una manera general. Para ello, se recurre a autores clásicos, artículos de periódicos científicos y páginas oficiales sobre el tema por medio de investigaciones documentales y bibliográficas. Se observa que el compromiso contemporáneo de promover actividades económicas, en alguna

\footnotetext{
1 Doutorando e mestre em Desenvolvimento e Meio Ambiente pela Associação em Rede PRODEMA, Universidade Federal de Pernambuco (UFPE). Membro pesquisador do Grupo de Pesquisa Sociedade e Natureza - Nexus (UFPE). E-mail: dweison.nunes@ufpe.br

2 Doutora em Geografia (Geografia Humana) pela Universidade de São Paulo (USP) e Pós-Doutorado na Universität Leipzig, Alemanha. Professora Titular da UFPE. Coordenadora do Grupo de Pesquisa Sociedade e Natureza - Nexus (UFPE). E-mail: torres@ufpe.br
} 
medida vinculadas a la sólida y duradera prosperidad social con la conservación de la naturaleza, se nos presenta materialmente inconcebible. Por lo tanto, la sostenibilidad constituyéndose como más una de las estrategias en el actual capitalismo por la cual algunos agentes público-privados buscan la legitimación de un determinado status quo.

Palabras clave: Capital. Políticas públicas. Desarrollo sostenible.

\section{Introdução}

Pensar os antecedentes das crises social e ambiental contemporâneas, no que se refere as suas determinações, requer um esforço para além dos fenômenos que, aparentemente, se apresentam isolados e/ou desconectados de uma maneira geral. Logo, parte-se da assertiva de que os fenômenos de precarizações sociais e ambientais que a humanidade tem experimentado historicamente, nas diversas escalas, têm a ver e estão conectados a um processo estrutural de produção social e apropriação da natureza cujo solo fundante está no capitalismo.

No século XIX, partindo dessa natureza capitalista, é mister pontuar os esforços de Marx \& Engels (2005) para compreender e mostrar os aspectos basilares pelos quais essa sociedade se reproduzia (que perduram até os dias atuais). Em resumo, seus escritos refletem sobre as práxis e as consequências dessa (re)produção capitalista, ao mesmo tempo em que buscam abstrair muitas de suas mistificações (ideologias, para muitos) até então naturalizadas como verdade nesse contexto histórico. Em especial, os ideais de prosperidade e de modernização para todos e todas. Mais adiante se discorrerá um pouco mais sobre essa ótica.

Já na segunda metade do século vinte, Berman (1986), ao citar Marx \& Engels (2005), se utiliza da frase tudo que é sólido desmancha no ar para defender a tese de que o ideal de modernização instituído como o modelo a ser seguido e alcançado pelos países e sociedades rumo à prosperidade, em verdade, se configurou como uma ideologia pela qual o fim seria a precarização social - a exploração de uma classe sobre a outra, por exemplo - e a artificialização da natureza. Subsumida no projeto de modernização e de progresso, a natureza é racionalizada e substituída por maquinários industriais e outros objetos técnicos, especialmente vinculados à adição de tecnologias cada vez menos integradas (SANTOS, 2010) ao projeto contemporâneo de sustentabilidade socioambiental.

Aliás, dentre muitas, a sustentabilidade torna-se, na atualidade, uma das palavras mais reiterativas, presente em narrativas e em outras alternativas logísticas utilizadas por agentes públicos, privados ou pela via mais trivial: em parceria público-privado, objetivando aprovações de projetos econômicos ou mesmo de continuação e ampliação de atividades correlatas. Adicionalmente, esse termo vem sendo, com frequência, inserido no cotidiano das pessoas e não raramente copiado por elas de modo descompromissado ${ }^{3} \mathrm{em}$ redes sociais e em seus discursos diários com familiares, no trabalho etc.

O paradoxo está no fato de, principalmente, em razão de projetos e de atividades retoricamente sustentáveis é que emergem e são reiterativos quanto (ou mais) retratos de desigualdades sociais e impactos ambientais via mudanças climáticas, desmatamentos, poluições hídricas etc. (SILVA; GOMES, 2018; SILVA, 2018). Assim, a sustentabilidade associada ao fator econômico, que prioriza ganhos sociais e ambientais, não se sustenta, na prática, quer numa escala planetária, quer regional e localmente. Por isso mesmo, talvez, seja mais uma das estratégias e adequações pelas quais o Capital e, por conseguinte o capitalismo, têm se sociometabolizado (para citar LESSA, 2013; MÉSZÁROS, 2011). Ensejando reflexões acerca do tema numa perspectiva de totalidade, ou seja, o seu estado da arte, considerando o

\footnotetext{
${ }^{3}$ Em muitos casos, a palavra é utilizada sem qualquer compromisso com a práxis. É como reclamar do consumo e ao mesmo tempo ser um consumista desenfreado. Ou mesmo, falar de reciclagem e não separar e destinar os resíduos adequadamente (grifos do autor).
} 
seu movimento histórico consubstanciado por mediações econômicas e políticas, sustentadas por argumentos sociais e ambientais.

De início, convêm analisar a etimologia da palavra sustentabilidade. O website Significados a concebe como uma derivação de "sustentável", de "sustentar"; do latim sustentare, "aguentar, apoiar, suportar, segurar, agarrar" (SIGNIFICADOS ${ }^{4}$, s/d, s/p). Sob esta ótica, a sustentabilidade pressupõe servir de apoio a fim de segurar algo (pessoas, atividades... discursos etc.) ao ponto de suportá-lo(a). Em seu viés socioambiental, a teoria é a de que a sustentabilidade promova a harmonia entre atividades econômicas que garantam a conservação da natureza e a melhoria dos aspectos sociais em determinados territórios (BOFF, 2012). Em outros termos, sua imprescindibilidade retórica pode ser associada à capacidade de a natureza e a sociedade suportarem (servirem de apoio, segurarem e agarrarem) as atividades econômicas (o vice-versa se aplica?), em especial aquelas potencialmente impactantes, e, por vezes, consideravelmente excludentes do ponto de vista social.

A questão é sob que materialidades a sustentabilidade está assentada? Convêm, por exemplo, lembrar das agendas oriundas de acordos políticos - conferências da Organização das Nações Unidas (ONU), em especial. A cada nova atualização (vigente agenda 2030), se evidenciam as frustrações pelos objetivos e metas não alcançados, ao mesmo em que se aumentam as promessas rumo à tão sonhada sustentabilidade. É oportuno pontuar que, em nome dessa mesma sustentabilidade, paradoxalmente, ao mesmo tempo em que os números econômicos de alguns agentes aumentaram exponencialmente, se vislumbram precarizações sociais e degradações ambientais ainda maiores, e isso em escala planetária. $\mathrm{O}$ que nos impele a questionarmos: quem, de fato, se favorece (e tem se favorecido) do uso da palavra sustentabilidade? Quem está suportando quem ou o quê? Segurar e agarrar para e a serviço de quem ou o quê?

Destarte, a problemática que se apresenta sob o amplo leque do conceito sustentabilidade e suas adjetivações, se constitui sob a factual e permanente contradição de seu tripé econômico, social e ambiental. Em outros termos, um desses pés - o econômico, notadamente - não integra harmonia com o social e o ambiental, precisamente por ser basilado e condicionado pelo crescimento exponencial ad infinitum (HARVEY, 2016). Característica fundamental para compreender as recorrentes e intermináveis publicações sobre impactos e violações socioambientais em nível planetário, em decorrência de intentos públicos e privados ditos sustentáveis.

No âmbito dessa dialética, será possível encontrarmos exemplos práticos de atividades econômicas com sustentabilidade, que sinalizem para prioridades sociais e ambientais e não apenas lucrativas? Ou o que se vê é um modelo de desenvolvimento sustentável consolidado por uma sustentabilidade meramente retórica, devidamente apropriada por corporações públicas e privadas para fins de fortalecer a economia de mercado?

Considerando o contexto introdutório, o presente artigo buscar refletir sobre as contradições que emergem do pseudo imperativo socioambiental contemporâneo - a sustentabilidade em suas várias faces - cuja naturalização tem contribuído, sobremaneira, para o aumento de desigualdades sociais e degradações ambientais de uma maneira geral.

Para tanto, recorremos a autores clássicos, artigos de periódicos científicos e páginas/notícias oficiais sobre o tema por meio de pesquisas documental e bibliográficas. Assim, o artigo está dividido em três seções. A primeira, versando sobre as particularidades do capitalismo e o papel do Estado nesse contexto - em termos contemporâneos e de gênese. A segunda, se utiliza das contribuições concebidas por Berman (1986), no que se refere ao processo não acabado de modernização da sociedade capitalista, contextualizado ao que se fala hoje sobre o tema. Finalmente, a terceira busca realçar, a partir de exemplos contemporâneos,

\footnotetext{
${ }^{4}$ Disponível em: <https://www.significados.com.br/sustentabilidade>.
} 
a dialética entre os fenômenos de precarização social e apropriação da natureza, consubstanciados por intentos governamentais e corporações públicas e privadas sob o argumento da sustentabilidade.

\section{Sobre o Capitalismo e a Função do Estado: considerações}

O capitalismo avançado, que se apresenta no atual contexto globalizado, se constitui como o principal modo de reprodução socioeconômica, pelo qual as sociedades de países, ditos capitalistas, buscam sua reprodução social, e, consecutivamente, mantêm relações com a natureza, nem sempre de forma harmoniosa. Nesse sentido, vale questionar até que ponto os imperativos econômicos contemporâneos constituem efetividade na perspectiva de uma totalidade social e ambiental rumo ao desenvolvimento sustentável.

Notadamente, o entendimento desse questionamento e, ademais, acerca de como o capitalismo tem se perpetuado ao longo dos últimos três séculos, perpassa pela atuação do Estado, especialmente, em que pese a adoção de políticas públicas. Em adição, corrobora-se com o que sustentam Mészáros (2011), Lessa (2013) e Paniago (2000) quando afirmam que, independentemente das metamorfoses pelas quais o Estado tem passado desde sua gênese, suas funções continuam sendo as mesmas: tão somente estar a serviço de uma classe dominante economicamente, a fim de torná-la, também, politicamente dominante.

Nesse sentido, historicamente as funções assumidas pelo Estado apresentam, pelo menos, três faces amplamente difundidas: o liberalismo, o keynesianismo e o atual neoliberalismo. Moraes (1997) ao tratar do liberalismo clássico, no qual o Estado, na condição de instância de poder público, atua de maneira a não intervir nas questões econômicas, evidenciando-se os fundamentos que emergiram nos séculos XVIII e XIX a partir de Smit, e que endossaram, segundo o autor, a ideia de que

[...] o mundo seria melhor - mais justo, racional, eficiente e produtivo - se houvesse livre iniciativa, se as atitudes econômicas dos indivíduos (e suas relações) não fossem limitadas por regulamentos e monopólios estatais. Uma doutrina que prega a necessidade de desregulamentar e privatizar as atividades econômicas, reduzindo o Estado a funções bastante definidas. Estas funções constituem apenas parâmetros bastante gerais para as atividades livres dos agentes econômicos (MORAES, 1997, p. $01)$.

Essa prática perdurou até a chegada da crise capitalista experimentada na primeira metade do século XX, cujas consequências foram as duas grandes guerras. Os ideais de Smit já não eram eficazes, emergindo, então, a necessidade intervencionista do Estado nas questões econômicas. É nessa ótica que se inicia o Estado Keynesiano, rotineiramente chamado de o Estado de bem-estar social, idealizado logo após a segunda guerra mundial e presente numa vasta literatura como os trinta anos dourados do capitalismo (LESSA, 2013). Para muitos pesquisadores, a sociedade civil experimentou os ganhos sociais advindos do modelo econômico citado, principalmente pela inserção e regulação do Estado na economia e pela adoção de políticas públicas de ordem social.

Esses trinta anos dourados, entre 1945 e 1975, marcado pelo Estado de bem-estar social, se caracterizaram, entre outras coisas, por retirar da iniciativa privada a exclusividade das funções econômicas face a mediação do Estado. Políticas públicas em educação básica, saúde, investimentos em infraestrutura e seguridade social são alguns dos exemplos do que se disseminou com o advento do Estado de intervenção a favor da classe trabalhadora (PANIAGO, 2000; LESSA, 2013). E, adicionalmente "uma maior requisição do Estado, que se faz presente através das políticas de incentivos fiscais, subsídios de toda ordem, financiamentos com taxa de juros reduzida e investimentos necessários para a estabilização do sistema como um todo" (PANIAGO, 2000, P. 10). 
Para Lessa (2013), na realidade esse período se tratou de um axioma, uma mistificação introduzida e devidamente incorporada pelo sistema (do capital), a fim de justificar (no sentido de obter o consenso) e, assim, dar continuidade ao estado da arte. $\mathrm{O}$ autor assinala que, apesar dos aparentes e ínfimos ganhos sociais oriundos de políticas públicas pela classe social que realizava trabalho, em verdade, não alteraram em nada a lógica de expansão e acumulação de Capital, uma vez que os dados econômicos apontaram para um substancial crescimento econômico de agentes privados, em virtude, justamente, dessas políticas.

Já o Neoliberalismo, fase atual do modelo capitalista de (re)produção socioeconômica, é fruto, precisamente, da crise vivenciada pelo Estado de Bem-estar social. Alguns fatos explicam a nova orientação para as reformas estatais: as crises do petróleo em 1973 e 1979, a derrocada do bloco socialista (Perestroika e Glasnost) e a crise econômica atribuída aos estados centrados no Welfare State, além da emergência tecnológica que transforma os processos produtivos; redefinindo o trabalho e o mundo das comunicações. Como revela Leme (2010, p. 130) esses "fatores influíram diretamente sobre a forma de organização e de integração dos mercados, desta vez não mais sob a regulação dos Estados Nacionais, mas, sim, numa lógica espacial multilateral ensejando um Estado mínimo".

Fundamentada no preceito liberal clássico e adaptada às novas dinâmicas capitalistas, a autonomia do mercado financeiro foi apontada como sendo essencial à superação da crise, em especial, a do petróleo. Implicando, também, na eliminação de muitos pactos regulatórios de ordem estatal, a privatização do Estado e a "adoção de medidas de liberalização e desregulamentação dos mercados". Como exemplo, a criação do "sistema de taxas de câmbio flutuantes, interferência de financeiras privadas na determinação dos preços das moedas, liberalização dos fluxos de capitais, abolição dos controles sobre o movimento dos capitais" (PANIAGO, 2000, p. 04).

Segundo Paniago (2000), tais condições foram postas como imprescindíveis à reestruturação do sistema econômico, para fins de crescimento. Em outros termos, o então Estado que atuava num contexto, através do qual as políticas públicas sociais eram socioeconomicamente viáveis, agora já não servia de valia ao sistema adotado. Contraditoriamente, esse Estado Keynesiano tornou-se, finalmente, a raiz do problema, e, por consequência, algo a ser superado, abrindo as portas ao Neoliberalismo (MÉSZÁROS, 2011; PANIAGO, 2000).

Adicionalmente, emergiram os elementos determinantes para que o Estado contemporâneo se convertesse, de forma evoluída, em Educador; logo, como afirmam Carvalho et al. (2014, p. 74), sua função passou a incorporar "além do aparato governamental, também o aparato 'privado' de hegemonia, isto é, as instituições superestruturais privadas que se encontram na sociedade civil", concebendo, dessa maneira, a sua Teoria Ampliada do Estado.

Nessa nova configuração, o Estado, por via da sociedade civil, busca a hegemonia pretendida pela classe dominante, que, por sua vez, é exercida através de intentos desenvolvimentistas, ou seja, uma política de promoção e cooptação, objetivando aliados mediante o direcionamento político e ideológico, em suma, pelo consenso. De outro lado, temse a sociedade política, pela qual a classe dominante opera de forma ditatorial implícita, rotineiramente chamada de democracia, e/ou explicitamente baseada no autoritarismo, por onde desempenha seu papel dominador político por intermédio da coerção.

Coutinho (1981, p. 92) ilumina essa discussão, ao sustentar que "enquanto a sociedade política tem seus portadores materiais nos aparelhos repressivos de Estado (controlados pelas burocracias executiva e policial-militar), os portadores materiais da sociedade civil são os que Gramsci chama de 'aparelhos privados de hegemonia', ou seja, organismos sociais coletivos voluntários e relativamente autônomos em face da sociedade política”.

A fusão coercitiva e consensual faz emergir uma organização sociopolítica, atuando e colaborando reciprocamente aos ideais capitalistas de reprodução. Carvalho et al. (2014, p. 72) 
ao tratarem dessa questão, especificamente no que concerne à opinião pública, afirmam que "quando o Estado promove uma ação popular, ele pode criar previamente, através dos instrumentos de propaganda, a opinião pública adequada. Daí porque existe a luta pela conquista dos monopólios dos órgãos de opinião pública (rádio, jornais, televisão)".

\section{Quando Tudo que é Sólido Desmancha no Ar: a Dialética Contemporânea}

Uma questão inicial nos parece importante ser colocada: as sociedades basiladas em formas de produção capitalista coexistem em meio ao dilema da modernidade, aparentemente não acabado, sequer devidamente apreendido com suficiente rigor: o processo contínuo de modernização. Sim, muito se fala em neomodernismo, quando em realidade ainda se busca, e, portanto, algo a ser atingido: o moderno. Esse constante vir a ser, próprio do capitalismo, figura como algo importante para o debate contemporâneo, sobretudo, das contradições que emergem do pretendido sólido e duradouro desenvolvimento sustentável.

A visão de modernidade revelada por Marx \& Engels (2005, p. 87) pode ser definida pelo fragmento textual que se segue (tornando-o, também, um tanto quanto desafiador do ponto de vista da reflexão e de sua interpretação): "tudo que é sólido desmancha no ar, tudo que é sagrado é profanado, e os homens são finalmente forçados a enfrentar com sentidos mais sóbrios suas reais condições de vida e suas relações com outros homens".

Noutros termos, para a cultura moderna não há espaço para a estabilidade e/ou solidez material, ao contrário, essa sociedade é constituída por princípios que, por vezes, provocam sua autodestruição; aspecto que tentamos detalhar o quanto possível no contexto deste artigo. Não obstante, o autor aponta que "O único espectro que realmente amedronta a moderna classe dominante e que realmente põe em perigo o mundo criado por ela à sua imagem é aquilo pelo que as elites tradicionais (e, por extensão, as massas tracionais) suspiravam: uma estabilidade sólida e duradoura" (BERMAN, 1986, p. 94).

Assim sendo, o pensamento modernista (estendido ao contemporâneo) tem como aspecto basilar a pressa pelo novo, que, por sua vez, engendra transformações e/ou metamorfoses das coisas através de sua destruição, bem como a instabilidade e inovação vinculadas ao que se pode inferir como aquilo que poderá vir a ser, ou ainda, aquilo que poderia ser, já não é mais; enfim, tudo que é sólido desmancha no ar.

No fragmento textual "[...] temos aí a emergência de um mercado mundial. À medida que se expande, absorve e destrói todos os mercados locais e regionais que toca" (BERMAN, 1986, p. 89) revela-se uma determinação diluidora de tudo que é sólido no âmbito dos desejos e reinvindicações humanas no capitalismo, e isso historicamente falando. Como exemplo, as atividades de escala local, sejam elas artesanais (pesca, agricultura familiar etc.) e/ou industriais de pequeno porte, não conseguem acompanhar o ritmo frenético do consumo mundial. Logo, são engolidas e dão lugar a maquinários sofisticados, trazendo monopolização de capital, por agora concentrado cada vez mais nas mãos de poucos. Com efeito, os trabalhadores do e no campo propriamente dito são transformados em aglomerados urbanos. Ao subjetivarem as consequências dessas perdas materiais, tomam consciência de uma nova realidade - opressora e desigual.

Tal qual Marx \& Engels (2005) explanaram, esse pensar modernista burguês, com seu incansável dinamismo revolucionário, traz consigo outro aspecto essencial à reflexão: $a$ submissão da natureza ao homem. Esse conceito é familiar, considerando o terreno em que nos encontramos ao nos depararmos com processos acentuados de degradação ambiental - local e globalmente - decorrentes das atividades humanas para fins de mais-valia. Essa submissão, eventualmente é causada por aquilo que é próprio da modernidade, como afirmaram Marx \& Engels, cujo temário foi retomado nas análise de Berman (1986, p. 93), quando afirma que essa 
sociedade "não pode subsistir sem constantemente revolucionar os meios de produção", e/ou ainda, "todas as novas relações, recém-formadas, se tornam obsoletas antes que se ossifiquem".

Então, a visão de progresso e crescimento modernos, está associada às transformações cíclicas - destruir para construir - que constituem tão-somente sua autodestruição. Em outras palavras, reitera Berman (1986, p. 94), "dizer que nossa sociedade está caindo aos pedaços é apenas dizer que ela está viva e em forma". Logo é possível concluir que o atual modelo capitalista é resultante de um processo revolucionário orientado à inovação, que tem relação umbilical com o acúmulo de capital solapado por desejos e ambições de uma classe dominante que, paradoxalmente, continua a engendrar (gênese e contemporâneo) desigualdades e conflitos sociais, degradações à natureza etc. sob a égide do desenvolvimento - que, nesse caso, nada mais é do que crescimento econômico - e do progresso, pelos quais buscam, initerruptamente, racionalizar a relação sociedade-natureza à sua imagem.

Diante disso, é interessante e fundamental refletir sobre a forma como é apreciado o conceito de desenvolvimento por Santos et al. (2012, p. 59): a partir de dimensões política, econômica, social e ambiental, os autores trazem considerações sobre sua gênese (crescimento), bem como sobre sua complexidade enquanto conceito interdisciplinar. Pontuam que o desenvolvimento pode servir, de um lado, como "[...] uma estratégia de reprodução do capital e de controle social, cuja finalidade consiste em corrigir distorções econômicas, políticas e sociais do sistema capitalista". E de outro, como "[...] uma gestão participativa, em que a sociedade, a comunidade, a família e o indivíduo sejam protagonistas e não espectadores da ação do Mercado ou do Estado".

Dentre outras interpretações, é possível inferir que o desenvolvimento é uma palavra (conceito) que, assim como a sustentabilidade e várias outras aqui citadas, assume um poder ideológico grandioso. A depender do contexto e interesses para os quais é utilizada, pode provocar alienações, conflitos e desigualdades; por outro lado, talvez, igualdade social, melhor distribuição de renda, desenvolvimento sustentável etc. Acerca disso, Bakhtin (2010, p. 14) afirma que "a palavra é a arena onde se confrontam os valores sociais contraditórios", como também, "a comunicação verbal implica conflitos, relações de dominação e de resistência, adaptação ou resistência à hierarquia, utilização da língua pela classe dominante para reforçar seu poder etc".

Tais considerações são importantes para compreensão de como alguns conceitos, aparentemente comprometidos com as resoluções dos males sociais e ambientais - a sustentabilidade -, são incorporados ao discurso a fim de constituírem um falso social necessário (para citar Lessa, 2013), cuja pretensa é dar legitimidade a um determinado status quo. Assim, o conceito atual de sustentabilidade incluído na agenda política de programas de governo e de empresas privadas, em geral, configura uma contradição à medida que

"[...] tudo o que a sociedade burguesa constrói é construído para ser posto abaixo. "Tudo o que é sólido" - das roupas sobre nossos corpos aos teares e fábricas que as tecem, os homens e mulheres que operam as máquinas, às casas e os bairros onde vivem os trabalhadores, às firmas e corporações que os exploram, às vilas e cidades... tudo isso é feito para ser desfeito amanhã, despedaçado ou esfarrapado, pulverizado ou dissolvido, a fim de que possa ser reciclado ou substituído na semana seguinte, e todo o processo possa seguir adiante...” (BERMAN, 1986, p. 97).

A citação acima traz a visão dialética da cultura moderna. De um lado, concebe meios de produção revolucionários, basilados em inovações tecnológicas, que possibilitaram grandes avanços à sociedade como um todo. De outro lado, os bens criados apresentam a desconfortável característica de serem planejados para tornarem-se obsoletos e de serem destruídos em curto espaço de tempo. Particularidade que se apresenta como uma das consequências da modernização: o constante e permanente vir a ser, a busca pela constante e incansável inovaçãorenovação, objetivando ganhos maiores de capital excedente. Nesse contexto, a sociedade 
capitalista é resumidamente orientada pelo dinheiro adquirido linearmente através da M-D-M (Mercadoria-Dinheiro-Mercadoria).

Assim, a ideia ininterrupta de inovação traz à tona o que Berman (1986) denomina de Niilismo, uma espécie de perda de referenciais, valores, crenças etc., que faz das atividades humanas - fundamentalmente, a partir das mediações que dão origem ao pensar moderno - um abismo; encoberto por uma máscara que destroça e desmancha tudo aquilo que outrora fora sólido. Nesse sentido, esse niilismo ou essa perda de referenciais, concebe a essa sociedade moderna, alienações acerca de sua própria criatividade. Nessa ótica, o autor nos impele a refletir acerca da seguinte definição: "[...] uma sociedade que libertou tão formidáveis meios de produção e troca, é como a feiticeira, incapaz de controlar os poderes ocultos desencadeados por seu feitiço" (BERMAN, 1986, p. 97).

Decerto, à medida que essa autodestruição inovadora é condição primordial à continuidade desse modelo de desenvolvimento, as alienações precisam ser permanentemente renovadas pelos desejos e impulsos incansáveis e infinitos. A dialética dessa peculiaridade é, sem dúvidas, a destruição factual de possibilidades humanas igualitárias e imbuídas de justiça social e de respeito à natureza, que, talvez, pudessem tornar-se sólidas e duradouras. Verificase, portanto, a notória necessidade revolucionária de uma sociedade que busque e construa valores menos alienantes e efêmeros e que transite por caminhos de práxis que desencadeiem iguais oportunidades de desenvolvimento aos seus habitantes.

\section{A Sustentabilidade que Naturaliza o Artificial}

Sob que materialidades pode-se sustentar, minimamente, o conceito tão difundido de sustentabilidade? Está ou será essa interação entre o econômico, o social e o ambiental possível de ser materializada a partir de atividades econômicas, atualmente artificializadas sobremaneira por técnicas basiladas em função de maquinários cada vez mais sofisticados e pela tecnologia da informação? Precisamente, para este estudo, a responsabilidade socioambiental assumida (retoricamente) por corporações públicas e privadas constituem materialidade em suas práticas cotidianas? Talvez, os exemplos que se seguem, possam responder, em parte, tais questionamentos.

Nosso primeiro exemplo remete às corporações privadas. O estado do Pará, região norte do Brasil, experimenta a dialética da sustentabilidade. Em fevereiro deste ano, o Tribunal de Justiça do Pará (TJ-PA) determinou que a empresa multinacional norueguesa Hydro Alunorte reduzisse suas atividades de mineração em $50 \%$, além da interdição de sua bacia de rejeitos, que segundo o TJ-PA, funcionava de forma irregular ${ }^{5}$. $\mathrm{O}$ fragmento textual do desembargador Iran Sampaio, responsável pela interdição, sustenta que "a conduta da empresa demonstra total desrespeito com a população de Barcarena e gera contaminação às pessoas e riscos a curto, médio e longo prazo à saúde" (G1 PA, 2018b, s/p). A empresa, que atua na produção de alumina no município de Barcarena desde 1995, difunde em seu website a missão pela qual são basiladas suas atividades: Sustentabilidade e Responsabilidade Social (HYDRO ALUNORTE, s/d, s/p). Todavia, de acordo com o Instituto Evandro Chagas (IEC), citado na reportagem do G1/PA (G1 PA, 2018b), as práxis da organização são constituídas pela contaminação ambiental de rios, especialmente, por metais pesados bauxita e chumbo (rejeitos), cuja consequência é a precarização social de populações ribeirinhas, constatando-se, ainda, que a empresa jamais teve capacidade de tratar seus efluentes (inclusive, com fontes de descartes de resíduos

\footnotetext{
${ }^{5}$ Vale ressaltar que essa constatação não expõe nada de novo. Ainda em 2009, o IBAMA já havia multado a empresa em R \$ 17,1 milhões por vazamento de rejeitos; expondo a população local a vulnerabilidades, gerando mortandade de peixes e destruição significativa da biodiversidade; valores até fevereiro de 2018, ainda não pagos. De acordo com a procuradoria geral da república do Pará, o histórico de acidentes ambientais da Hydro no município de Barcarena alcança um a cada ano, considerando sua gênese em 1995 (G1 PA, 2018a).
} 
clandestinos), tampouco apresenta plano emergencial para o caso de rompimentos e/ou desastres naturais.

Os resultados oriundos de atividades econômicas com sustentabilidade da chamada tragédia de Mariana, em Minas Gerais, evento considerado como o maior desastre socioambiental do país, é outro exemplo relevante. A empresa Samarco, uma joint-venture da nacional Vale e da anglo-australiana BHP Billiton, promovia (e, em continuum) em seu website os pilares da sustentabilidade nos quais está assentada: "responsabilidade com o bem-estar das pessoas e da sociedade, assim como o cuidado com o meio ambiente..." (SAMARCO, s/d, s/p). Seja como for, o que se viu foram impactos à natureza e à sociedade local em alta magnitude. Para se ter ideia, com o rompimento da barragem, 1,2 milhão de pessoas foram afetadas pela falta d'água e 1.200 desabrigados em 35 municípios de Minas Gerais e dois do Espírito Santo (PORTO, 2016). Além da destruição de pequenos vilarejos "a lama percorreu $663 \mathrm{~km}$ ao longo dos rios Gualaxo do Norte, Carmo e Doce, chegando à foz deste e afetando seu ecossistema marinho em área de reprodução de espécies marinhas" (PORTO, 2016, p. 01-02). Ou seja, mais uma vez a sustentabilidade que não se sustenta minimamente na prática.

Os exemplos podem ser citados noutras escalas. No âmbito do continente Sulamericano, pode-se mencionar o departamento (Estado) Chocó, na Colômbia. Dotado de uma riqueza peculiar em recursos naturais, especialmente de fonte hídrica, seus munícipes convivem com altos índices de precarização social e ambiental. Os dados sinalizam para as atividades econômicas vinculadas à mineração como coautoras dessa problemática. Todavia, uma vez mais, a retórica difundida pelas empresas que ali atuam (por exemplo, a multinacional sulafricana Anglo Gold Ashanti), ressalta o compromisso sustentável para fins de sustentabilidade. De forma literal, a empresa argumenta que "respetamos los derechos humanos y el medio ambiente" (ANGLO GOLD ASHANTI, s/d, s/p).

Entretanto, em face de políticas públicas de privatização (fruto do estado neoliberal), pelas quais é dado o empoderamento a empresas multinacionais, os rios contaminados apresentam altos índices de metais pesados (como mercúrio, cianeto etc.) cuja consequência é a mortandade de peixes e outros animais aquáticos, bem como doenças associadas a alterações genéticas em populações locais, com centralidade em crianças e recém nascidos (LATECONCHOCO, 2012; JIMÉNEZ, 2015; CEJSTD, 2016; VARGAS, 2014). Qualquer semelhança com os exemplos brasileiros não é pura coincidência.

Retornando à escala nacional, importa analisar os intentos governamentais sob a égide do desenvolvimento com sustentabilidade (SUAPE, s/d) Dentre outros, um exemplo do uso da sustentabilidade pode ser visto no território de Suape, no estado de Pernambuco - Brasil. Por meio da instalação de um Complexo Industrial Portuário (CIP) é notória a tentativa de inserção de uma racionalidade técnica - via tecnologia - nessa superfície, eventualmente alterando as territorialidades antes praticadas. Sob a égide da responsabilidade socioambiental e do desenvolvimento com sustentabilidade, e respaldado pelo Estado, a atuação do empreendimento pode ser explicada sob dois aspectos. Primeiro, suprimindo extensas áreas de vegetação permanente e consecutivamente ocasionando impactos ambientais na escala local; segundo, emergindo um processo desterritorializador por despossessão de populações locais de pescadores e pescadoras. Ambos os aspectos, consubstanciados pelos argumentos de interesse social e utilidade pública, que, segundo Silva (2018), servem apenas para mascarar o real projeto de desenvolvimento para o estado de Pernambuco, concebido na década de 1970, e que perdura até os dias atuais: substantivamente econômico.

São suficientemente claros os argumentos teóricos à legitimidade (efetividade) das leis ambientais que dispõem sobre a proteção florestal e ecossistemas interligados. Entretanto, a sustentabilidade pretendida aparece mais uma vez como insustentável. Na década de 1960, mesmo com o Código Florestal (BRASIL, 1965) em vigor, o então governo da ditadura militar, sob o argumento de modernização econômica, incentivou, financeira e fiscalmente, políticas 
públicas de implantação da pecuária como principal atividade de exploração econômica na região amazônica.

Pela ação política, também foram implementados projetos de assentamento que cumpriram, ao mesmo tempo, a função de alargamento da fronteira agrícola e reserva de mãode-obra por meio do incentivo ao acesso à terra, resultando em mais de um milhão de hectares de áreas de pastagens em degradação e áreas de capoeiras abandonadas (MESQUITA, 2006).

Em meados de 1970, mais de dez milhões de hectares já haviam sido desflorestados, culminando com a intensificação exploratória na década de 1980, cujo percentual se apresentava em $10 \%$ de área de floresta desmatada. Em termos comparativos, antes da década de 1970, constava apenas 1\% de desmatamento; entre os anos de 1970 e 2006 já havia cerca de $17 \%$ de ecossistemas desflorestados na região Amazônica. Alguns municípios $(13,6 \%$, na Amazônia), no ano de 2005, apresentavam índices de desmatamento em mais de $95 \%$ de sua cobertura florestal (PRATES; BRACHA, 2011). Números que evidenciam e resultam, segundo os autores, de políticas de governo utilizadas "para dinamizar economicamente a região por meio de investimentos próprios ou via concessão de incentivos fiscais e fundos de investimento, visando atrair capitais privados" (PRATES; BRACHA, 2011, p. 603), sobretudo através da criação de órgãos públicos de incentivo, em nome da sustentabilidade (econômica) do país.

O novo código florestal, configurado pela Lei no 12.651 (BRASIL, 2012) também não se mostra eficaz. Os dados analisados pelo Projeto de Monitoramento do Desflorestamento na Amazônia Legal (Prodes) apontam que, após alguns anos de estagnação, posterior a 2012 (ano de menor taxa de desmatamento), o cenário de perda florestal tem apresentado sucessivos aumentos. As informações mais recentes revelam que a efetividade das leis está muito aquém do mínimo aceitável. O calendário oficial para medir o desmatamento mostra que, entre agosto de 2015 e julho de 2016, a Amazônia perdeu $7.989 \mathrm{~km}^{2}$ de floresta, a maior taxa desde 2008 . Para se ter ideia, o valor equivale, no período analisado, ao desmatamento de 128 campos de futebol por hora de floresta, como afirma o Instituto de Pesquisa Ambiental da Amazônia (IPAM) (CRISTALDO, 2017).

Os dados em relação à Mata Atlântica também não são animadores. A Fundação SOS Mata Atlântica e o Instituto Nacional de Pesquisas Espaciais (INPE), em maio de 2017, apontaram o desmatamento de 29.075 hectares (ha), ou $290 \mathrm{Km}^{2}$, nos dezessete estados do bioma Mata Atlântica - representando aumento de 57,7\% em relação ao período anterior (20142015), referente a 18.433 ha. O que faz do acordo firmado - Nova História para a Mata Atlântica, popularmente utilizado com a \#Desmatamento Zero - pelos governos, aparentemente com objetivos de redução do desmatamento naquele ambiente, entre 2015 e 2018, se converta, precisamente, na \#Compromisso quase zero, tendo em vista que, dos dezessete estados que assinam o documento, apenas cinco estão no nível estabelecido: menos de 100 ha de desflorestamento (SOS, 2017). Contexto consubstanciado por políticas públicas que priorizam o crescimento econômico e não o tripé requerido pela sustentabilidade.

$\mathrm{Na}$ escala estadual, reaparece Pernambuco. De acordo com o Instituto Brasileiro do Meio Ambiente e dos Recursos Naturais Renováveis (IBAMA), os incentivos políticos autorizativos de supressão vegetal em nome da sustentabilidade industrial resultaram na redução da cobertura original de Mata Atlântica para menos de 3\%, hoje, totalmente fragmentada. Os maiores responsáveis pela perda florestal são os recentes processos de industrialização na Zona da Mata e na Região Metropolitana. Entre 2014 e 2016, os dados sobre o desflorestamento apontavam para 136 ha de floresta e mais de 790 ha de manguezais (SILVA, 2018; SOS, 2017).

Silva e Gomes (2018) sustentam que os dados sociais não justificam os índices de desmatamento, uma vez que a lei apenas permite a supressão vegetal nos casos de Interesse Social e/ou Utilidade Pública. Paradoxalmente, as atividades mencionadas contribuíram para a continuação e avanço de processos de exclusão social, altos índices de analfabetismo e de 
desemprego (cerca de 50 mil no mesmo período). A consequência disso está representada nos baixos Índices de Desenvolvimento Humano (IDH) nos municípios de Ipojuca e Cabo de Santo Agostinho, denominados de influência direta.

Na teoria, presente no documento que trata da exposição dos motivos para a aprovação do Código florestal de 1965, são relevantes as seguintes justificativas de seus idealizadores:

I - Tentativa visando a encontrar-se uma solução adequada para o problema florestal brasileiro cujo progressivo agravamento está a exigir a adoção de medidas capazes de evitar a devastação das nossas reservas florestais que ameaçam transformar vastas áreas do Território Nacional em verdadeiros descritos (BRASIL, 1965, s/p).

No código florestal de 2012, Lei 12.651, Art. $1^{\circ}$, tendo como objetivo o desenvolvimento sustentável, a lei reitera a "II - reafirmação da importância da função estratégica da atividade agropecuária e do papel das florestas e demais formas de vegetação nativa na sustentabilidade, no crescimento econômico, na melhoria da qualidade de vida da população brasileira" (BRASIL, 2012, p. 01). Observa-se que a sustentabilidade é sempre condicionada a subsidiar o crescimento econômico, ou seja, o sustentável utilizado para legitimar o modus operandi, claramente, insustentável. Os cenários supramencionados reforçam e destacam a contradição entre o que se diz na teoria, e o que se quer dizer, na prática.

Convêm sinalizar, portanto, que os intentos governamentais em nome do desenvolvimento sustentável e da sustentabilidade são, via de regra, falaciosos e enganosos. Primeiro, pelo fato de a palavra desenvolvimento nada mais ser que crescimento (econômico) (BOFF, 2012), sendo a adjetivação sustentável, meramente, uma forma de adequação às demandas contemporâneas pela suposta preocupação ambiental e com o bem-estar das pessoas.

A sustentabilidade emerge como um conceito complementar, justamente, para conceder legitimidade à retórica socioambiental, à medida que pressupõe a busca pelo crescimento econômico com responsabilidades sociais e com a natureza. Como revelado no Documentário Seremos história? (Before the flood), produzido pela National Geographic Channel, o aquecimento global e as mudanças climáticas são mais do que comprovados, todavia, são esquecidos e até mesmo desmentidos e ridicularizados (BEFORE the flood, 2018) pelos mesmos governos que, retoricamente, estariam em defesa da diminuição do uso de combustíveis fósseis. São os casos, no viés brasileiro, da bancada ruralista e da recente lei dos agrotóxicos, cuja aprovação é justificada pela indispensável sustentabilidade do agronegócio brasileiro (RELATÓRIO..., 2018).

Uma conclusão preliminar é a de que os compromissos econômicos alicerçados (no discurso) sob a égide do desenvolvimento sustentável, aliados ao dilema constantemente contraditório de sustentabilidade - o liame supostamente inseparável entre o social, o ambiental e o econômico - no final das contas, não cumprem com a pretensa harmonia massivamente difundida por corporações públicas e privadas (especialmente, se utilizando do marketing ambiental). Aspecto essencial para melhor compreender o que, na contemporaneidade, se convenciona como o Estado de bem-estar socioambiental (no âmbito das políticas públicas) e como responsabilidade socioambiental (na esfera corporativa-privada): no campo da materialidade é apenas mais um falso social necessário à plena e material sociometabolização do Capital ${ }^{6}$.

Cabe, para finalizar, considerar o seguinte paradoxo: ao que tudo indica, muitas atividades contemporâneas vêm sendo legitimadas (de maneira ilusória) por conceitos

\footnotetext{
${ }^{6}$ Para Lessa (2013) o Estado é verdadeiramente um agente facilitador, portanto, complementar aos imperativos capitalistas de reprodução, que, por sua vez, acabam por criar artifícios, no sentido de adequar-se às barreiras que o sistema do capital tem encontrado ao longo da história. Assim, o Estado, adjetivado como de bem-estar ou ainda de bem-estar socioambiental torna-se um falso social necessário para adequação de atividades econômicas.
} 
desvinculados da realidade. Não raramente, são construídos (no intelecto) pelas mesmas entidades governamentais e privadas que, por meio de práxis contraditórias, acabam por deslegitimar tais conceitos. É sob essa ótica pseudointelectual e longe da realidade que, acreditamos, tenha emergido a sustentabilidade, a ponto de converter-se numa retórica falaciosa, cujo fim é sustentar o insustentável. Não é fácil precisar, exatamente, até que ponto se concretizam as previsões de Santos (2010, p. 117-119), ao assinalar que a humanidade estava, está ou estará em transição de período, no qual os marginalizados e excluídos do processo globalizatório detém de todas as ferramentas para constituir uma mudança efetiva ao paradigma do capitalismo. Mas, sem dúvida, o autor é assertivo ao revelar que os lugares - locais onde as vivências cotidianas fazem emergir vivências sempre renovadas - reclamam pela revalorização do plural. Logo, o de não ser unificado, tampouco tomados pelo totalitarismo de técnicas sustentáveis que a maioria da população sequer tem a sua disposição.

Antes de finalizarmos esta seção, cabe abrir um breve parêntese. Embora alguns poucos queiram negar, pode-se afirmar que é consensual o reconhecimento da existência e, mais ainda, da gravidade dos problemas socioambientais com os quais a sociedade contemporânea de modo de produção capitalista tem sido obrigada a conviver, cotidianamente. Também, é consensual a compreensão da Educação Ambiental (EA) como uma importante ferramenta de combate e ação para a superação desses problemas, considerando a sua gênese desde a década de 1970, fortemente associada a movimentos ambientalistas, e, em tempos recentes, amplamente difundida e cada vez mais institucionalizada como instrumento de política pública (GUIMARÃES, 2016). A questão primordial se vincula à reflexão de que esse reconhecimento não significa, de modo algum, que as propostas e ações nesse campo de pesquisa estejam sendo eficazes ou mesmo consensuais.

Vejamos o seguinte consenso: é fato que, hoje, se conhece muito mais sobre os conceitos de desenvolvimento sustentável e de sustentabilidade do que se sabia quarenta anos atrás; ainda, é fato que a grande maioria dos indivíduos acredita ser importante a preservação da natureza, para esta e para as futuras gerações. Os cenários contemporâneos também mostram que a EA ganhou espaço considerável na sociedade, seja no meio acadêmico ou no cotidiano das pessoas. No entanto, o paradoxo quanto ao consenso reside na assertiva de que essa mesma sociedade degrada o meio ambiente muito mais, hoje, do que fazia quarenta anos atrás, mostrando que o aumento no nível de consciência sobre a crise ambiental, proporcionalmente, não a diminuiu (BOMFIM; PICCOLO, 2011).

A pergunta simples e objetiva é: por que, então, fazemos isso? Será ausência de materiais didático-pedagógicos e produção acadêmica insuficiente para a formação continuada de educadores ambientais para a EA? Será em função da falta de suportes técnicos e apoios institucionais para que as teorias de sustentabilidade se materializem no cotidiano? Sugerimos que as questões discutidas nesta pesquisa podem contribuir para responder essas perguntas.

Fechamos o parêntese, advertindo o leitor que a proposição deste artigo não é, de modo algum, realizar uma discussão acurada sobre teorias de EA. Antes, o objetivo foi trazer à superfície as contradições internas e de práxis associadas ao conceito de sustentabilidade que, dentre outros, é um argumento (quase consensual) norteador das teorias e práticas de educadores ambientais. Diante disso, consideramos que este estudo traz uma importante contribuição para o campo da EA e para educadores ambientais, colaborando, em alguma medida, com o processo de reflexão crítica que, desde sempre, torna-se elemento necessário (COSTA; LOUREIRO, 2019) para este campo de pesquisa. Afinal, como advertem Mészáros (2008) e Serna, Gomes e Silva (2018) pensar a educação [ambiental] para além do capital e do capitalismo é um compromisso revolucionário, em que a perspectiva de ruptura e superação de determinados conceitos e paradigmas precisam estar na ordem do dia. 


\section{Considerações finais}

O compromisso contemporâneo de promover atividades econômicas, em alguma medida conectadas à sólida e duradoura prosperidade social e orientadas à conservação da natureza, se apresenta materialmente inconcebível, logo, configurando-se como mais uma ideologia para fins teleológicos bem definidos. Nesse sentido, apesar de ser imprescindível e urgente, o imperativo socioambiental a ser alcançado via sustentabilidade está longe de uma efetividade satisfatória. Outrossim, vem sendo incorporada a estratégias mercadológicas, a fim de legitimar atividades meramente econômicas, contribuindo, paradoxalmente, para o aumento de desigualdades sociais e impactos à natureza. Assertiva, embora desconfortável, parece inevitável ser colocada em face da discussão teórica-conceitual e dos exemplos relatados ao longo deste artigo.

Constatação que pode, em parte, ser compreendida pela não integrabilidade entre o econômico, o social e o ambiental, uma vez que o capitalismo atual (e de gênese) pressupõe exploração de uma classe sobre outra(s) classe(s) pela via da espoliação e da exclusão sociais. E, ainda, considerando suas determinações acumulativas e de expansão (MÉSZÁROS, 2011), basiladas no crescimento exponencial (HARVEY, 2016), é difícil imaginar a conservação da natureza, em termos conservacionistas e ou preservacionistas, como requerem as leis que dispõem sobre ambientes protegidos. Não por acaso, as recorrentes notícias sobre desmatamentos, mudanças climáticas, poluições hídricas etc., cujas consequências recaem sobre a sociedade e a natureza, especialmente, sobre os marginalizados e excluídos do processo contemporâneo assentados sob a égide da sustentabilidade.

A contribuição de Berman (1986) reafirma a ambiguidade existente no conceito de sustentabilidade. A pressa pelo novo e o constante vir a ser característicos de sociedades de crescimento econômico, fazem dos pretendidos ambientes ecologicamente equilibrados e bem de uso comum para presentes e futuras gerações, utopias, logo, substantivamente ideológicos. No capitalismo contemporâneo, as práxis que constituem a sua dinâmica sociometabólica tendem a racionalizar ambientes (natureza e sociedade), reduzindo e subsumindo práticas existentes ao seu movimento, logo, substituindo-as e naturalizando-as segundo sua orientação.

Assim, tudo que é sólido desmancha no ar e levanta-se novamente, só que agora, com uma outra roupagem. Na contemporaneidade vale questionar, por exemplo, os motivos pelos quais os problemas ambientais e sociais continuam a aumentar, mesmo com todo o conhecimento e maquinários sofisticados de monitoramento oriundos do avanço tecnológico de nosso século. Harvey (2016) sustenta que já se conhece suficientemente as soluções para os problemas sociais e ambientais, todavia, as soluções não são postas em prática por serem incompatíveis à dinâmica sociometabólica do Capital e do capitalismo.

Conclui-se, insistindo-se para o necessário debate muito mais comprometido com as resoluções dos conhecidos problemas estruturais com os quais as sociedades do capitalismo convivem. Essas soluções, acreditamos, vão muito além da sustentabilidade retórica disseminada por alguns agentes público-privados. Por sua vez, aparentemente, muito comprometidos em legitimar e dar continuidade aos seus projetos econômicos, e, paradoxalmente, descompromissados com a promoção social das pessoas e com a conservação da natureza.

Diante disso, é oportuno refletir acerca dessa perspectiva: será que no discurso moderno/contemporâneo há lugar para relações sólidas e duradouras a ponto de se conseguir melhores condições de vida comprometidas com a conservação da natureza, já que é de práxis dessa sociedade que todas as relações - sociais, políticas e ambientais - se tornem obsoletas antes que ossifiquem?

Fica a expectativa de que pesquisadores e educadores do campo de pesquisa em EA, e de outros campos de pesquisa similares, utilizem as discussões teóricas aqui expostas como 
mais um elemento para aprofundar o debate acerca da temática socioambiental e os limites e possibilidades da EA, dando atenção especial e olhar crítico para o conceito de sustentabilidade, que, ao nosso juízo, se apresenta teoricamente inconcebível e, portanto, com notória impossibilidade objetiva, do ponto de vista de sua exequibilidade nas realidades socioambientais.

Fica, ainda, uma outra expectativa, a de que haja tempo para refletir sobre a advertência de Benjamin (2015) de que nada foi mais desastroso e destrutivo para a classe operária alemã do que a opinião conformista de que ela nadava a favor das correntezas do progresso, e que o correr da história, naturalmente, propiciaria a todos uma satisfação socioeconômica, que, obviamente, não se confirmou. Ou seja, não existe apenas uma, mas, sim, várias correntezas. Nesse caso, a questão é saber nadar, muitas vezes contra determinadas correntezas que, por sua vez, podem nos levar a ser apenas expectadores de nosso tempo histórico.

\section{Referências}

ANGLO GOLD ASHANTI. s/d. Homepage da empresa. Disponível em: <https://www.anglogoldashanticolombia.com/derechos-humanos/>. Acesso em: 28 abr. 2020.

BAKHTIN, M. Marxismo e Filosofia da Linguagem: problemas do Método sociológico na Ciência da Linguagem. 14 ed. São Paulo: HUCITEC, 2010.

BEFORE the flood (Seremos história?). Executive Producer: Martin Scorcese. Washington D.C.: National Geographic Chanel, 2018.

BENJAMIN, W. A obra de arte na era de sua reprodutibilidade técnica. Porto Alegre: L\&PM, 2015.

BERMAN, M. Tudo que é Sólido Desmancha no Ar: A Aventura da Modernidade. Tradução de Carlos F. M. e Ana M. L. Ioriatti. São Paulo: Companhia das Letras, 1986.

BOFF, L. Sustentabilidade: o que é, o que não é. Petrópolis: Vozes, 2012.

BOMFIM, A. M.; PICCOLO, F. D. Educação ambiental crítica: a questão ambiental entre os conceitos de cultura e trabalho. REMEA - Revista Eletrônica do Mestrado em Educação Ambiental, [S.1.], v. 27, p. 184-195, jan. 2011. Disponível em: <https://periodicos.furg.br/remea/article/view/3236>. Acesso em: 07 maio. 2020.

BRASIL. Portal da Câmara dos Deputados. Lei $n^{\circ} 4.771$, de 15 de setembro de 1965. Trata da Exposição de Motivos No 29-65, do Ministro da Agricultura. Disponível em:

<http://www2.camara.leg.br/legin/fed/lei/2012/lei-12651-25-maio-2012-613076-normaatualizadapl.pdf>. Acesso em: 29 abr. 2020.

BRASIL. Casa Civil. Lei $n^{o}$ 12.651, de 25 de maio de 2012. Dispõe sobre a proteção da vegetação nativa... e dá outras providências. Brasília: Casa Civil, 2012. Disponível em:

<http://www.planalto.gov.br/ccivil_03/_ato2011-2014/2012/lei/112651.htm>. Acesso em: 29 abr. 2020 .

CARVALHO, A. C. et al. Fundamentações Teóricas sobre o Estado Capitalista: uma perspectiva marxista. Revista Ciências Sociais em Perspectiva, Cascavel, v. 22, n. 1, p. 67-83, jul. 2014. Disponível em: <http://e-revista.unioeste.br/index.php/ccsaemperspectiva/article/view/9415>. Acesso em: 07 maio. 2020.

CENTRO DE ESTUDIOS PARA LA JUSTICIA SOCIAL TIERRA DIGNA - CEJSTD. La Minería en Chocó, en Clave de Derechos. Investigación y propuestas para convertir la crisis socio-ambiental 
en paz y justicia territorial. Bogotá: Tierra Digna, 2016. Disponible en:

<https://lamineriaenchoco.tierradigna.org/>. Acceso en: 29 abr. 2020.

COSTA, C. A.; LOUREIRO, C. F. Interdisciplinaridade, Materialismo Histórico-Dialético e Paradigma da Complexidade: Articulações em Torno da Pesquisa em Educação Ambiental Crítica. Revista pesquisa em educação ambiental, Rio Claro, v. 14, n. 1, p. 32-46, 2019. Disponível em: $<$ http://www.periodicos.rc.biblioteca.unesp.br/index.php/pesquisa/article/view/12187>. Acesso em: 07 maio. 2020.

COUTINHO, C. N. Gramsci. Porto Alegre: L \& PM, 1981.

CRISTALDO, H. Amazônia perde $7.989 \mathrm{~km}^{2}$ de floresta, maior desmatamento desde 2008. Agência de Notícias, Brasília, 09 jan. de 2017. Disponível em:

$<$ http://agenciabrasil.ebc.com.br/geral/noticia/2017-01/amazonia-perde-7989-km2-de-floresta-maiordesmatamento-desde-2008>. Acesso em: 29 abr. 2020.

DEZ pontos para entender o vazamento de barragem de mineradora que contamina Barcarena, no PA: Alto índice de chumbo e outros metais contaminam a região. G1 PA, Belém, 24 fev. de 2018a. Disponível em: <https://g1.globo.com/pa/para/noticia/10-pontos-para-entender-o-vazamento-debarragem-de-mineradora-que-contamina-barcarena-no-pa.ghtml>. Acesso em: 29 abr. 2020.

GUIMARÃES, M. Por uma educação ambiental crítica na sociedade atual. Revista Margens Interdisciplinar, [S.1.], v. 7, n. 9, p. 11-22, 2016. Disponível em:

<https://periodicos.ufpa.br/index.php/revistamargens/article/view/2767>. Acesso em: 07 maio. 2020.

HARVEY, D. 17 Contradições e o fim do capitalismo. São Paulo: Boitempo, 2016.

HYDRO ALUNORTE. s/d. Homepage da empresa. Disponível em: https://www.hydro.com/ptBR/a-hydro-no-brasil/Sustentabilidade/>. Acesso em: 28 abr. 2020.

JIMÉNEZ, C. A. ¿Cómo es el avance en la cobertura de acueducto en Colombia? El Tiempo, Bogotá, 22 mar. de 2015. Disponible en: 〈http://www.eltiempo.com/archivo/documento/CMS-15445939〉.

Acceso en: 29 abr. 2020.

JUSTIÇA manda mineradora reduzir produção e embarga bacia de rejeitos. G1 PA, Belém, 28 fev. de 2018b. Disponível em: <https://g1.globo.com/pa/para/noticia/justica-embarga-funcionamento-damineradora-hydro-apos-vazamento-de-rejeitos-no-pa.ghtml>. Acesso em: 29 abr. 2020.

LATECONCHOCO. 2012. Blog Wordpress. Contaminación del agua en el Chocó: Identificación del problema. Disponible en: <https://lateconchoco.wordpress.com/2012/09/10/contaminacion-delagua-en-el-choco-identificacion-del-problema/> . Acceso en: 29 abr. 2020.

LEME, A. A. Neoliberalismo, Globalização e Reformas do Estado: reflexões acerca da temática. Revista Barbarói, Santa Cruz do Sul, s/v, n. 32, p. 114-138, jan./jul. 2010. Disponível em: $<$ http://pepsic.bvsalud.org/scielo.php?script=sci_arttext\&pid=S010465782010000100008\&lng=pt\&nrm=iso>. Acesso em: 29 abr. 2020.

LESSA, S. Capital e Estado de Bem-estar: O caráter de Classe das políticas públicas. São Paulo: Instituto Lukács, 2013.

MARX, K.; ENGELS, F. O Manifesto Comunista. Tradução de Álvaro Pina. São Paulo: Boitempo, 2005. 
MESQUITA, A. G. G. Impactos das queimadas sobre o ambiente e a biodiversidade acreana. Brasília: CPTEC/INPE, 2006. Disponível em:

<http://queimadas.cptec.inpe.br/ rqueimadas/material3os/impacto_queimadas_ambiente_biodiversida de.pdf>. Acesso em: 29 abr. 2020.

MÉSZÁROS, I. A educação para além do capital. São Paulo: Boitempo Editorial, 2008.

MÉSZÁROS, I. Para Além do Capital: rumo a uma teoria da transição. Tradução Paulo C. C., Sérgio Lessa. São Paulo: Boitempo, 2011.

MORAES, R. C. C. 1997. Blog Wordpress. Liberalismo e Neoliberalismo: uma introdução comparativa. Disponível em:

<https://reginaldomoraes.files.wordpress.com/2011/06/lib_neolib_compara.pdf〉. Acesso em: 29 abr. 2020.

PANIAGO, M. C. S. O controle do capital: uma impossibilidade objetiva. Serviço Social \& Sociedade, São Paulo, n. 64, p. 5-33, nov. 2000. Disponível em:

$<$ http://www.cristinapaniago.com/yahoo_site_admin/assets/docs/o_controle_do_capital.185204615.pd f>. Acesso em: 29 abr. 2020.

PORTO, M. F. S. A tragédia da mineração e do desenvolvimento no Brasil: desafios para a saúde coletiva. Cad. Saúde Pública, Rio de Janeiro, v. 32, n.2, e00211015, fev., 2016. Disponível em: $<$ http://www.scielo.br/scielo.php?script=sci_arttext\&pid=S0102-

311X2016000200302\&lng=en\&nrm=iso >. Acesso em: 29 abr. 2020.

PRATES, R. C.; BRACHA, C. J. C. Os processos de desenvolvimento e desmatamento da Amazônia. Revista Economia e Sociedade, Campinas, v. 20, n. 3, p. 601-636, dez. 2011. Disponível em: $<$ http://www.scielo.br/scielo.php?script=sci_arttext\&pid=S010406182011000300006\&lng=en\&nrm=iso>. Acesso em: 29 abr. 2020.

RELATÓRIO da Lei dos Agrotóxicos é aprovado; plenário votará após eleições. Correio Braziliense, Brasília, 26 jun. de 2018. Disponível em:

<https://www.correiobraziliense.com.br/app/noticia/brasil/2018/06/26/interna-brasil,690951/relatorioda-lei-dos-agrotoxicos-e-aprovado-plenario-votara-apos-elei.shtml>. Acesso em: 29 abr. 2020.

SAMARCO. s/d. Homepage da empresa. Missão e Valores. Disponível em: <http://www.samarco.com/missao-e-valores/>. Acesso em: 29 abr. 2020.

SANTOS, L. S. et al. Desenvolvimento: Um Conceito Multidimensional. Revista eletrônica DRdDesenvolvimento Regional em debate, Contestado, s/v, Ano 2, n. 1, p. 44-61, jul. 2012. Disponível em: 〈http://hdl.handle.net/10400.22/1858>. Acesso em: 29 abr. 2020.

SANTOS, M. Por uma Outra Globalização: do pensamento único à consciência universal. 10 ed., Record: Rio de Janeiro, 2010.

SERNA, A. G.; GOMES, E. T. A.; SILVA, D. N. S. Puntuando algunos de los desafíos de las universidades latinoamericanas en el futuro presente. Avaliação, Campinas, v. 23, n. 3, p. 648-664, 2018. Disponível em: <https://www.scielo.br/scielo.php?script=sci_arttext\&pid=S141440772018000300648>. Acesso em: 30 abr. 2020.

SIGNIFICADOS. Website. Repositório de significados, conceitos e definições [Online]. Disponível em: <https://www.significados.com.br/sustentabilidade>. Acesso em: 28 abr. 2020. 
SILVA, D. N. S. Desafios e Perspectivas Socioambientais Presente Futuro Reflexões a partir do Complexo Industrial Portuário De Suape - Brasil. 2018. 120p. Dissertação (Programa de Pósgraduação em Desenvolvimento e Meio Ambiente - PRODEMA) - Universidade Federal de Pernambuco, Recife, 2018.

SILVA, D. N. S.; GOMES, E. T. A. Discurso ambiental e a apropriação da natureza: o caso do Complexo Industrial Portuário de Suape - Pernambuco - Brasil. Boletim Goiano de Geografia, Goiânia, v. 38, n. 1, p. 49-67, maio 2018. Disponível em:

<https://revistas.ufg.br/bgg/article/view/52814>. Acesso em: 28 abr. 2020.

SOS - FUNDAÇÃO MATA ATLÂNTICA. 2017. Homepage da Organização. Desmatamento da Mata Atlântica cresce quase $60 \%$ em um ano. Disponível em:

<https://www.sosma.org.br/106279/desmatamento-da-mata-atlantica-cresce-quase-60-em-um-ano/>. Acesso em: 29 abr. 2020.

SUAPE - Complexo Industrial Portuário. Homepage da empresa. Missão, Visão e Valores. Disponível em: 〈http://www.suape.pe.gov.br/pt/institucional/missao-visao-e-valores>. Acesso em: 07 mai. 2020.

VARGAS, T. M. Agua potable, el sueño de Lloró, Chocó. El Espectador, Bogotá, 04 mayo de 2014. Disponible en: <http://www.elespectador.com/noticias/nacional/agua-potable-el-sueno-de-lloro-chocoarticulo-490398>. Acceso en: 29 abr. 2020. 